\title{
To what extent are land resource managers preparing for high-end climate change in Scotland?
}

\author{
Miriam Dunn $^{1}$ (D) $\cdot$ Mark D. Rounsevell ${ }^{1} \cdot$ Henrik Carlsen $^{2} \cdot$ \\ Adis Dzebo $^{2}$ - Tiago Capela Lourenço ${ }^{3}$ - Joseph Hagg ${ }^{4}$
}

\begin{abstract}
We explore the individual and institutional conditions and the climate information used to underpin decision-making for adaptation to high-end climate change (HECC) scenarios in a land resource management context. HECC refers to extreme projections with global annual temperature increases of over $4{ }^{\circ} \mathrm{C}$. We analyse whether HECC scenarios are used in the adaptation decision-making of stakeholders who will tackle the potential problem. We also explore whether the adaptation actions being considered are pertinent only to future climate change or whether other drivers and information types are used in decision-making (including
\end{abstract}

Electronic supplementary material The online version of this article (doi:10.1007/s10584-016-1881-0) contains supplementary material, which is available to authorized users.

Miriam Dunn

miriam.dunn@ed.ac.uk

Mark D. Rounsevell

mark.rounsevell@ed.ac.uk

Henrik Carlsen

henrik.carlsen@sei-international.org

Adis Dzebo

adis.dzebo@sei-international.org

Tiago Capela Lourenço

tcapela@fc.ul.pt

Joseph Hagg

joseph@sniffer.org.uk

1 Institute of Geography, School of Geosciences, University of Edinburgh, Drummond street, Edinburgh EH8 9XP, Scotland

2 Stockholm Environment Institute, Stockholm, Sweden

3 Faculty of Sciences, University of Lisbon, Lisboa, Portugal

4 Adaptation Scotland/SNIFFER, Edinburgh, Scotland 
non-climate drivers). We also address the role of knowledge uncertainty in adaptation decision-making. Decision-makers perceive HECC as having a low probability of occurrence and so they do not directly account for HECC within existing actions to address climate change. Such actions focus on incremental rather than transformative solutions in which non-climate drivers are at least as important, and in many cases more important, than climate change alone. This reflects the need to accommodate multiple concerns and low risk options (i.e. incremental change). Uncertainty in climate change information is not a significant barrier to decision-making and stakeholders indicated little need for more climate information in support of adaptation decision-making. There is, however, an identified need for more information about the implications of particular sectoral and cross-sectoral impacts under HECC scenarios. The outcomes of this study provide evidence to assist in contextualising climate change information by creating usable, cross-sectoral, decision-centred information.

\section{Introduction}

The committed warming due to the level of greenhouse gases (GHG) currently in the Earth's atmosphere suggests that achieving the target of the Paris Agreement to limit global temperature increases to $1.5^{\circ} \mathrm{C}$ is an ambitious one, and reaching it is not a foregone conclusion. Global emissions of GHG are currently tracking on a high-end trajectory, viz. higher than the most fossil-fuel intensive emissions scenarios developed by the Intergovernmental Panel on Climate Change (IPCC; Jordan et al. 2013; IPCC (WGIII) 2014). Good risk management involves preparing for the worst, but hoping for the best. The reality of the worst is that the world is currently headed for an average increase in temperature of $4{ }^{\circ} \mathrm{C}$ and beyond (Gasser et al. 2015; Stafford Smith et al. 2011). The current high-end trajectory would lead to severe climate change impacts, as reported for sea-level rise (Golledge et al. 2015), flood risk (Alfieri et al. 2015) and water scarcity (Schewe et al. 2014) among others. Impacts and adaptation to high-end climate change (HECC) are currently a key focus of European Union (EU) project funding, with three complementary projects that focus on regional and local impacts and adaptation across a range of land, water and coastal ecosystems (High-end climate research EU website 2016). While intergovernmental emphasis is currently on mitigation of emissions to reach the $1.5^{\circ} \mathrm{C}$ target, these EU projects recognise that good risk management involves preparing for higher levels of adaptation than we hope are necessary.

How such adaptation occurs will depend on individual and collective decision-making (Adger et al. 2005), and so understanding the conditions influencing decision-makers is a step towards producing information that supports their capacity to adapt to climate change. The purpose of the work presented here is to provide insight into stakeholders' knowledge and decision-making in regard to HECC scenarios based on qualitative evidence from a land resource management case study. The goal is to understand the conditions (challenges) and the types of climate change information that influence land resource managers when making decisions about adapting to climate change. Improving understanding of this bottom-up perspective can then inform the development of better contextualised adaptation strategies that account for current conditions.

\subsection{Background}

The decision-making of individuals and groups is influenced or constrained by many factors which give them different perspectives on the goals and objectives of adaptation 
(Poteete and Ostrom 2004; Adger et al. 2009; Murray-Rust et al. 2014). Factors that influence individual decision-makers' adaptation decision-making include cognitive biases and judgement heuristics, which have been shown to affect people's perceived adaptive capacity irrationally and also their risk perception (Grothmann and Patt 2005; Adger et al. 2009). One such bias is the "optimistic bias" or "unrealistic optimism" (Grothmann and Patt 2005; Weinstein 1980). This bias results in people perceiving their own risk of being affected by a particular threat to be smaller than the average risk. A group's adaptation decision-making at the policy level is constrained by issues including inertia, cultures of risk denial and other phenomena (Adger et al. 2009). Factors that have been shown to limit adaptation at the organisation level include the following: lack of adequate information about climate change impacts, lack of resources at the local authority level, conflicting interests, negative impacts from existing policies at lower levels of governance, and the difficulty in assessing and implementing adaptation options (Adger et al. 2009; Berkhout et al. 2006; Crabbé and Robin 2006; Poteete and Ostrom 2004).

An individual's or group's adaptation decision-making is also constrained by the institutional context within which they operate, including, for example, regulatory structures, property rights and social norms (Adger et al. 2005; Adger et al. 2009; Powell and DiMaggio 2012). Institutions play a critical role in influencing adaptation decision-making in the land resource management sector through both policy instruments and direct interventions (Murray-Rust et al. 2014). Examples relevant to this research include, but are not limited to, the United Nations Framework Convention on Climate Change, the European Union's Common Agricultural Policy and the Scottish Government's Climate Change Adaptation Programme (Scottish Government 2013).

Collective action describes much of the group decision-making within the land resource management sector (Adger 2010). It is argued that the quality of such formal institutions as the state influences the capacity of groups to act in their collective interest (Ostrom 1990); this is the case for climate change adaptation. To adapt to climate change, state intervention and planning is necessary, but it is also necessary for individuals and groups to engage in collective action (Adger 2010). Collective action requires networks of actors and flows of information between those actors to enable decision-making (Adger 2010). Such networks are generally referred to as social capital (Adger 2010). The theory of social capital describes how individuals act towards other actors within the society to achieve their own and the collective good (Adger 2010). The state can act as a facilitator of social capital for climate change adaptation, for example through providing a physical or regulatory infrastructure that resonates with social norms (Adger 2010). Factors that have been shown to facilitate collective action for adaptation include the following: the rigidity or fluidity of the institutional context, the characteristics of the decision-making group, technology, how management benefits are distributed, and the actions of government and external actors, including regulation and economic incentives (Adger et al. 2009; Adger 2010; Poteete and Ostrom 2004).

Decision-centred adaptation decision-making puts climate into perspective within the applicable decision context and considers all of the contributing factors, for example economic priorities, environmental issues, political and social factors, demographics and regulation. In contrast, the climate-centred framework assumes that decisions are most importantly influenced by climate projections, and does not recognise that climate is only one factor, of which many others also influence the adaptation decision to be made. The 
need to understand and work within stakeholders' existing decision-making processes is well established in the literature (e.g. Mase and Prokopy 2014; Howden and Jacobs 2015). Although the decision-centred framework is increasingly acknowledged as resulting in better decision-making than the climate-centred framework (e.g. Dessai et al. 2009; Daron et al. 2015), climate change adaptation policy continues to be dominated by a climate-centred approach (Smith 2015).

The continuance of the climate-centred approach is in part influenced by the "uncertainty fallacy" (Lemos and Rood 2010) - that is, the "belief that the systematic reduction of uncertainty in climate projections is required in order for the projections to be used by decision-makers". But this has been shown to be incorrect through examples that demonstrate that decision-makers are adept at making adaptation decisions on the basis of incomplete or uncertain information (Tribbia and Moser 2008; Bryson et al. 2010; Heckbert et al. 2010; Street and Nilsson 2014; Lourenço et al. 2014). Such uncertainty does not prevent decisions from being made (Bryson et al. 2010). Therefore, the presence of uncertainties in future climate information should not derail the decision process (Heckbert et al. 2010) - but rather should increase the focus on robust, decision-centred decision-making.

\subsection{Objectives of the research}

The theoretical underpinnings discussed above are used to address the key research questions: Are HECC scenarios used in the adaptation decision-making of stakeholders who will need to deal with the potential impacts? If yes, then are they acting to adapt in line with the high-end impacts? Conversely, are they considering adaptation actions that are only pertinent to more moderate levels of future climate change? What are the most important information types used for their decision-making (including non-climate drivers)? What are the barriers to using that information? And finally, what is the role of uncertainty in adaptation decision-making for stakeholders? These questions address the objective of this research: to provide insight into stakeholders' knowledge and decision-making in regard to HECC scenarios based on qualitative evidence from a land resource management case study.

\section{Method}

Semi-structured interviews were conducted with decision-makers engaged in the management of Scotland's land resource sectors to gather empirical data about their adaptation decision-making. Details of how this analysis was performed as follows: first, a brief introduction to the HECC scenarios used is presented, followed by an overview of the study region, and then a description of the data collection and analysis process.

\subsection{HECC scenarios for Scotland}

The HECC scenarios referred to in this work are sourced from spatial (mapped) model output of projected temperature and precipitation changes for the early, middle and late twenty-first century. This model output was sourced from the UKCIP website, as well as directly from project partners at the Danish Meteorological Institute who produce output from the HadGEM Earth System Model, downscaled to a spatial resolution of $50 \mathrm{~km}$. The "high-end" of emissions refers to representative concentration pathway 8.5, the highest of the IPCC's current 
emissions pathways. Examples of these HECC scenarios that were used in this work can be found in Electronic Supplementary Material I.

\subsection{The study region-Scotland}

Under climate change, temperatures in Scotland are projected to increase significantly by the end of the century $\left(\sim 3{ }^{\circ} \mathrm{C}\right)$. There is a (relatively) advanced knowledge of high-end scenarios of climate change for this region - that is, there is a greater agreement between climate models about the likely changes than is the case for many other regions. Scotland was chosen as a case study because it is a leader in adaptation planning, especially in terms of integrating and financing adaptation. An example of this is the statutory requirement (under the Climate Change (Scotland) Act 2009) for Public Bodies to report on their climate change adaptation measures (Parliament of Scotland 2009; Scottish Government 2011). The 32 local councils within Scotland have begun adaptation measures in line with these requirements.

Individuals from organisations involved in the land resource management sector were chosen as the focus of interviews because they represent sectors of the Scottish rural economy which would be directly and indirectly impacted by high-end climate change. The land resource management sector is also one of the foci of the adaptation measures required within the Scottish Government's Climate Change (Scotland) Act. This region has demonstrated a mixture of bottom-up and top-down approaches to adaptation, and thus a deeper understanding of bottom-up constraints could help to further adaptation actions.

\subsection{Data collection and analysis}

Twenty in-depth face-to-face interviews were conducted with decision-makers in various locations across Scotland between March and June 2015. All interviews were conducted by the same interviewer and ranged in duration between half an hour and one and a half hours, depending on the responses given by the interviewee.

Stakeholders were identified and invited through existing contacts and local networks of practitioners that are maintained by SNIFFER (2015), a knowledge-brokering NGO that operates in the resilience and sustainability sectors in Scotland. Snowball sampling was also used (Biernacki and Waldorf 1981), wherein participants were asked to suggest other potentially suitable candidates. These stakeholders were selected against numerous criteria, based on a matrix developed and tested in similar stakeholder research by Gramberger et al. (2015) to achieve representativeness across categories. These criteria include demographics, sector, level of operation of the organisation, function of the stakeholder, level of operation of the stakeholder and organisational affiliation. The final selection of stakeholders consisted of representatives: from different sectors (with a focus on land resource management, e.g. forestry, agriculture, etc); at different levels of government (local, regional and federal), as well as NGOs and private business; within organisations that operate at different levels (locally, regionally, internationally); with different functions; and across the range of demographics.

Although participants' organisations are all broadly part of the land resource management sector, many of the organisations operate across several different sub-sectors. These include, but are not limited to the following: land use/land use management, biodiversity conservation, infrastructure, agriculture, water, forestry and transport. The types of organisations that these stakeholders represent include the following: governmental agencies, companies and 
enterprises (including SMEs), research organisations, inter-institutional networks/associations, practitioners/planners, business organisations, NGOs, legal authorities (including regulators) and charities.

The interviews were framed by a decision-centred approach to on the ground adaptation decision-making. The empirical data collection was guided by the research questions stated in Section 1. The interviews focused on the individual, collective and institutional conditions and decision-making processes that underpin adaptation to HECC. Sixteen questions were asked, with multiple sub-questions that focused on the context and support for decision-making for climate change adaptation. The interviews were recorded and transcribed, then analysed using both deductive (based on an answer key) and inductive (based on thematic; Attride-Stirling 2001) analysis. The interview and answer key templates are available in Electronic Supplementary Material II.

\section{Results}

Four key themes emerged from the interviews: (1) the use of HECC scenarios, (2) the barriers to use of climate change (including high-end scenarios) information, (3) socio-economic factors that influence decision-making and 4) the role of uncertainty in decision-making. These emergent themes from the interviews are explored in the following sections to analyse the conditions (challenges) that influence land resource managers when making decisions about adapting to climate change. They also support existing theory about the use of climate change information in adaptation decision-making. The following sections answer the research questions: Are HECC scenarios used in the adaptation decision-making of stakeholders who will need to deal with the potential impacts? If yes, then are they acting to adapt in line with the high-end impacts? Conversely, are they considering adaptation actions that are only pertinent to more moderate levels of future climate change? What are the most important information types used for their decision-making (including non-climate drivers)? What are the barriers to using that information? And finally, what is the role of uncertainty in adaptation decision-making for stakeholders? To provide context for answering these questions, the next sub-section presents an overview the types of decisions the interview participants are making. A brief overview characterisation of the interview participants themselves is presented in Electronic Supplementary Material III.

\subsection{Types of decisions made by participants}

Participants' roles in the decision-making process within their organisations vary. Eleven of the 20 participants are primarily advising or consulting other colleagues, including higher levels of management, on adaptation decisions rather than personally making them (these are mostly in the government sector). Other roles in the decision-making process include the following: being part of a team that creates overall adaptation policy/action plans within the organisation (these are mostly in the business sector), implementing adaptation measures within the organisation, implementing maintenance measures and lobbying others about adaptation within or outside the organisation. All of the 20 interview participants stated that adaptation-related decisions (where they are actually being made) are primarily bottom-up processes, in the sense that the organisation would first define/assess/evaluate objectives. Because interview participants represent a mixture of types of organisations, as well as 
different levels within decision-making processes, they exhibit aspects of both individual and collective action theories of decision-making (see Section 1).

The key methods used in participants' adaptation-related decision-making processes are as follows: expert judgement, real options, risk minimisation, cost-efficiency analysis/cost-benefit analysis, scenario analysis, probability analysis, multi-criteria analysis, formal political processes and sensitivity analysis. The types of information currently used by participants in these decision-making processes include visualisations (including GIS, scenarios, maps etc.), research-based outputs (primarily UKCP09 model output maps), information from research organisations (including boundary organisations), expert judgement and modelling of non-climate factors (e.g. tree growth models or business models). The majority (14 of the 20) of participants' organisations have made adaptation-related decisions. These decisions typically have a short to medium lead time and a medium to long consequence time, equalling a long decision lifetime, and therefore requiring action to address high-end climate change projections, which are anticipated to occur sooner than previously thought (Stafford Smith et al. 2011).

\subsection{Use of HECC information in adaptation decision-making}

The results indicate no constraints in accessing HECC information (Fig. 1, left); the issue is only whether or not this information is used in decision-making (Fig. 1, centre). HECC forms a part of the background "pool" of knowledge when decisions are made, and it influences the types of information these decision-makers provide to others when advising on decisions; but it is considered as one of several options, not the only nor the most probable one. This is consistent with the view expressed by participants and supported in the literature that a decision-centred, rather than climate-centred, approach is preferable for adaptation decision-making.

In most cases, specific temperature changes are not considered relevant to adaptation decision-making, which is generally focused on robust actions. Only a small number of

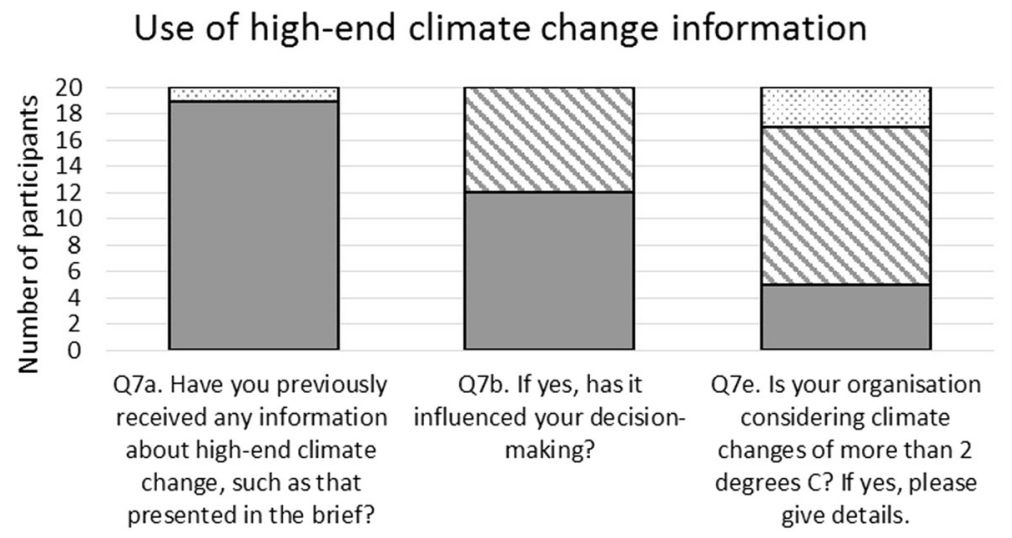

Question and response

$\square$ Yes $\square$ No $\square$ Non-response

Fig. 1 Use of HECC information by participants, including whether they had previously received this type of information (left), whether it has influenced their decision-making (centre) and whether their organisation is considering specific climate changes of greater than $2{ }^{\circ} \mathrm{C}$ (right) 
organisations specifically consider climate change of greater than $2{ }^{\circ} \mathrm{C}$ (Fig. 1, right), and for the most part, there is no consideration of a specific temperature threshold nor the differences between e.g. 2 and $3{ }^{\circ} \mathrm{C}$. In all cases, there is more concern for the potential impacts and the implications thereof, leading to a focus on broad, qualitative levels of change, rather than specific temperature thresholds. These themes indicate reasons for the discrepancy in numbers between the statement that HECC projections have influenced decision-making and the statement that the organisation is not specifically considering changes of greater than $2{ }^{\circ} \mathrm{C}$. Examples of how participants use the broad level climate change projections (without specific temperature thresholds) include the following: proving the need to include climate change adaptation in the corporate risk register, demonstrating the potential changes using visioning exercises to encourage authorities to take on adaptation issues in their development plans, decisions on whether existing areas continue to be planted with forests, and scenario planning in the development of flood risk management plans. There is no clear difference or pattern in use of types of climate information between participant or organisational types.

\subsection{Barriers to use of (any level of) climate change information}

The term "barriers" used in this section is defined as the perceived limitations to the extent of whether and how climate change information is used. According to views expressed by participants, the key limitations in the use of climate change information are usability and issues of understanding, not the uncertainty of the information (Fig. 2).

Participants' responses indicated that information is not usable because of the following: it is not adequately tailored to the decision-making circumstance, there is a lack of cross-sectoral information and it is often not presented in a format that is usable (or translated out of "researcher language"). The most common information received is probabilistic information about the likelihood of the changes in climatic variables and the direct climate impacts those changes might cause. From the interviews it can be deduced that, in most cases, available

\section{Limitations (by theme) to use of future climate change information for decision-making}

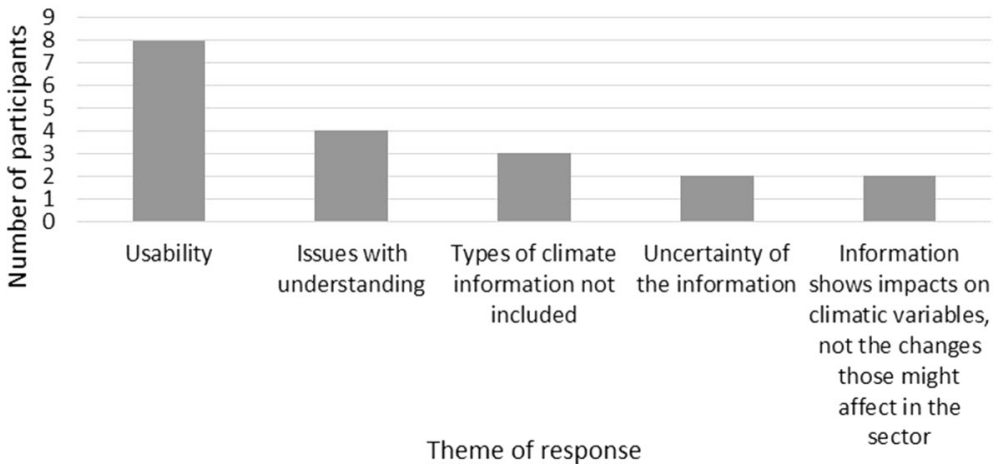

Fig. 2 A categorisation of the participants' perceived limitations to use of the future climate change information for decisionmaking. Note that there are a greater number of total responses in the specific limitations than in the general limitations. This is because each participant was only counted once (as to the theme of limitation) 
information does not show the sectoral implications that climate change might bring about (while cross-sectoral approaches are still not considered the norm, they are recognised as necessary to support adaptation decision-making). Participants also particularly expressed a perceived lack of projections of future flood events. Analysis of the interviews shows that understanding trade-offs in the spatial scale of information is considered key, but virtually nonexistent, while in some cases, technological barriers remain in using available information. These findings illustrate that climate variables alone do not influence decision-makingbecause adaptation decision-making is focused on impacts and therefore is decision-centred (Daron et al. 2015), not climate-centred. Uncertainty surrounding climate projections was only considered to be a limitation in the use of climate change information for adaptation decisionmaking by $10 \%$ of participants.

\subsubsection{Barriers in the use of HECC scenarios}

Where HECC information has not influenced decision-making, this is because of the following: the scenarios are considered to be "too far-fetched"; there is a lack of belief that world emissions are tracking the HECC projections; in some cases, the spatial scale is not adequate; the organisation uses general trends rather than specific figures or rates of change; numerous other (socio-economic) factors are considered to have a bigger influence on decisions; and participants are not sufficiently familiar with how to correctly use or interpret the information.

\subsection{Socio-economic factors that influence decision-making}

Climate change impacts will occur within the socio-economic context and will vary depending on the pathways that socio-economic variables follow in the future (Füssel 2007). Many different socio-economic variables influence climate adaptation decision-making. The future changes in all of the socio-economic factors are perceived to be highly uncertain because of their strong interrelationships.

Recommendations from participants about how to improve the usability of models for adaptation decision-making support the need to focus on providing properly contextualised, decision-centred rather than climate-centred information. They also focus on integrating socioeconomic changes (both direct and indirect impacts) into the information, providing more guidance on cross-sectoral impacts and making better use of visual tools and approaches. Climate is only one aspect of decision-making, and it is not the most important aspect. In most cases, non-climate factors are more important to decision-making - and guidance is needed about impacts from non-climate factors, showing sector-specific implications. It is not more precise temperature projections that are needed for adaptation decision-making, but rather better contextualised impacts, adaptation and vulnerability information.

\subsection{Uncertainty of changes to climatic variables is not a barrier to adaptation}

Climate change uncertainty, referring to the uncertainty of projected climatic changes, is a familiar term to participants and is discussed and understood by them primarily in qualitative, descriptive terms, although it is also communicated using probabilistic climate change futures. Problems in dealing with uncertainty in adaptation decision-making - and this is uncommonarise from the perceived difficulties associated with understanding the synergies between particular climate change and socio-economic change scenarios, not due to the presence of 
uncertainty per se. Nonetheless, uncertainty is not considered to be a significant barrier in taking action to adapt. However, uncertainty does affect the ways in which decision-makers choose to adapt, viz. decision-makers focus on incremental rather than transformative solutions.

\subsection{Challenges to implementing HECC adaptation measures - summary}

The majority of challenges to implementing HECC adaptation measures are not based on future climate change information (or lack thereof), but rather, on institutional conditions, including but not limited to political issues, the policy process, and financial and economic issues (notably funding and cost-benefit analyses; Fig. 3). These factors are often more demanding considerations than future climate change information.

Short political cycles influence decision-making processes regarding how far into the future adaptation planning can go; this reduces the focus on HECC (which requires a long-term view). It also makes transformative adaptation less likely, as it is easier to adjust incrementally rather than through transformation because of changing political circumstances and new climate change information.

\section{Discussion}

HECC scenarios are not currently regarded as most probable by the interview participants and therefore are not considered to be directly useful for adaptation decision-making. This could in part be explained by cognitive biases and judgment heuristics, which act to enhance the perception of good adaptive capacity and downplay the risks (Grothmann and Patt 2005). For example, the optimistic bias (Weinstein 1980) suggests that decision-makers would consider the risk of HECC affecting their organisation to be smaller than the average risk, and this may influence their decision-making with regard to adaptation. This type of decision is then confirmed in the decision-makers' thinking because HECC scenarios represent only

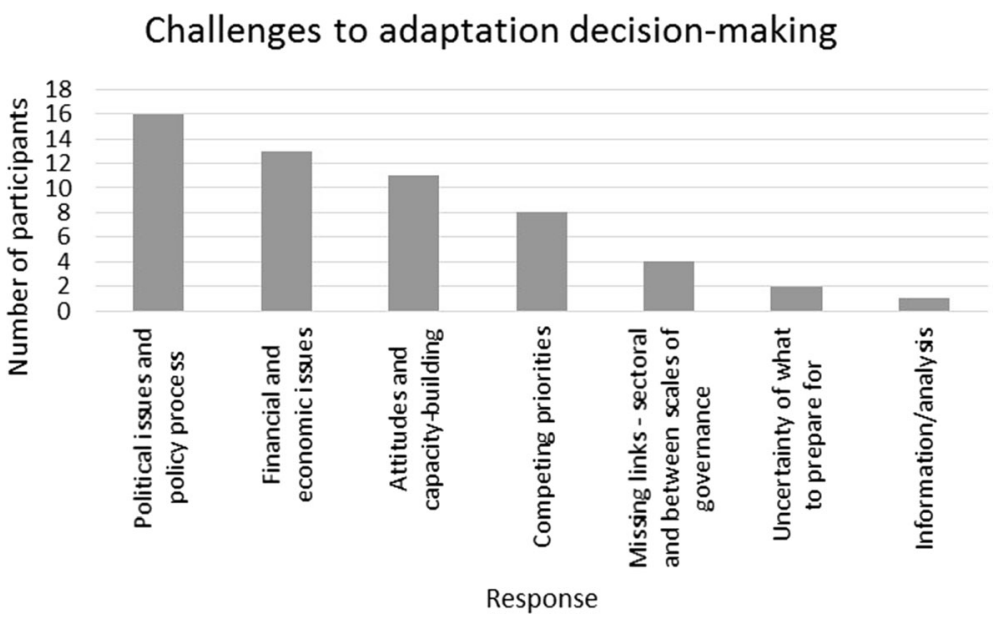

Fig. 3 Participants' thematic responses when asked about the challenges to adaptation decision-making 
one of a range of projections. Therefore, reaffirming their belief that it is less likely to affect their organisation, despite the evidence that global emissions are in line with or above the projected HECC pathways. This theory explains the seeming lack of urgency placed on adapting to HECC. In addition, the fact that HECC scenarios are sometimes considered "too far-fetched" suggests an inability to visualise possible futures under HECC scenarios in ways that are meaningful to some of these decision makers. This also suggests that they are unable to relate these to current decision making in a way that they can understand and act upon. This is a well-recognised dimension influencing adaptation decision-making (see for example Wyborn et al. 2016).

According to the participants, institutional decision processes that are highly influenced by timeframes of political and policy cycles (5-10 years on average) are one of the primary factors inhibiting adaptation to HECC being included in existing decision-making. The Scottish government has recently implemented good quality formal institutions related to climate change adaptation - in the form of regulation that requires all public bodies to address adaptation in their risk strategies and to provide updated adaptation action progress reports. This institutional context has facilitated increased levels of collective action on adaptation measures, and supports existing literature on factors that facilitate adaptation for collective action (e.g. Poteete and Ostrom 2004). It may also be influencing how many of these interview participants' organisations are making adaptation decisions. But it is yet in the early stages and therefore remains to be seen just how much sustained impact this regulation will effect.

The literature regarding enablers in the uptake of climate change information overwhelming centres on collaboration, interaction and bridging work and tailoring information, accessibility/ usability and agency capacity and training (Jones et al. 2016; e.g. Lemos et al. 2012). Improvements to climate change science are much less evident in the literature regarding how to best enable the uptake of climate change information (Jones et al. 2016), whereas improvements to climate change impacts information are considered to be important.

The finding that there is a perceived lack of probabilistic information about the likely future cross-sectoral changes in socio-economic variables and the indirect impacts thereof is common in the literature (e.g. Harrison et al. 2016). Such decision-centred, cross-sectoral examples of how to successfully adapt are considered salient for adaptation decision-making (Holman et al. 2016; Harrison et al. 2015; Jäger et al. 2015; Skourtos et al. 2015). This perceived lack may explain why these decision-makers do not find information about, for example, the differences between 2 or 3 degree temperature changes to be useful for their adaptation decision-making. It may also explain why the current manifestation of 'climate services' (European Commission 2015; Lourenço et al. 2015) has not been used to the extent expected by the climate modelling community-because it remains climate-focused rather than decision-centred. Focusing modelling resources to support adaptation on improving the contextualisation of, for example, impacts, adaptation and vulnerability information, rather than improving the modelling of specific climatic variables would begin to address this discrepancy.

These findings are mostly consistent with the existing literature on barriers to the use of climate change information for adaptation decision-making (e.g. Eisenack et al. 2014; Mase and Prokopy 2014; Jones et al. 2016). Some limited research has been conducted on the interdependencies between barriers and the dynamic changes that affect them (e.g. Cuevas 2016), but more is still needed.

To achieve this desired decision-sensitive contextualisation, greater efforts need to be put into co-producing information that fits within the decision-centred framework employed by decision-makers in land resource management. Using existing, trusted intermediaries, or 
"knowledge brokers", within boundary organisations may assist in implementing these strategies to help overcome the barriers that prevent better mutual understanding and interactions (Turnhout et al. 2013; Schlierf and Meyer 2013; Lemos et al. 2014). Boundary organisations such as Adaptation Scotland ${ }^{1}$, along with similar organisations in other regions and other countries, hold the potential to play a key role in this process of knowledge brokering, as trusted intermediaries with strong links to both knowledge providers and decision-makers (Turnhout et al. 2013). However, the level of success that boundary organisations are able to achieve is influenced by institutional conditions which affect their financial and human resources, as well as by the behaviour of individuals with (how engaged and progressive they are) respect to integrating new knowledge and practices.

The finding that uncertainty about projected future changes to climatic variables is not a significant barrier to decision-making supports existing literature showing that, in practice, uncertainty of climate change information is not a barrier to taking action to adapt to climate change (e.g. Lourenço et al. 2014; Tribbia and Moser 2008; Bryson et al. 2010; Heckbert et al. 2010; Lemos and Rood 2010; Street and Nilsson 2014; Dunn et al. 2015). This finding is also in line with a similar case study of coastal managers and their information needs for adaptation (Tribbia and Moser 2008), which showed that the uncertainties in climate change science were not considered a significant obstacle to managers taking action to adapt.

The finding that qualitative descriptions of uncertainty are more usefully employed than their quantitative counterparts supports the idea that a different approach should be taken to working uncertain climate projections into decision-making (Dessai et al. 2009), rather than requiring definite answers which climate projections cannot supply. This suggests that a qualitative, descriptive approach might be a better way for the scientific community to express uncertainty. This could involve representing uncertainties using the descriptive terms defined, for example, by the IPCC (Mastrandrea et al. 2010; their "likelihood"), rather than using the quantitative probabilities associated with each term. The former are more closely aligned with the qualitative, descriptive terms which decision-makers use to discuss uncertainty, and therefore fit well with existing decision-making processes, and are thus more likely to be correctly understood and correctly used. By using this information as one of several inputs to inform the decision-making process, decisions about adaptation strategies can be made even though deep uncertainties exist (Dessai et al. 2009).

\section{Conclusions}

Knowledge of HECC is relatively commonplace among interview participants, but HECC is not considered to have a high probability of occurring, and so existing actions to address climate change do not focus on adapting to HECC scenarios. Lack of usability of information (because it is not adequately contextualised or sufficiently cross-sectoral) and institutional decision processes that are highly influenced by timeframes of political and policy cycles are

\footnotetext{
${ }^{1}$ Adaptation Scotland, a public NGO which is funded by the Scottish Government, is an example of a boundary organisation in Scotland that works at a local level to integrate new and existing information about adapting to climate change and to see it through to implementation both in policy and on-ground within local communities. An example of how they help decision-makers to manage the uncertainty associated with future socioeconomic conditions is by providing online visualisations of alternative possible future scenarios; in these scenarios decision-makers can make different adaptation changes that explore robust solutions under the different potential socio-economic changes.
} 
two of the primary factors inhibiting HECC from being included in existing adaptation decision-making. The first of these barriers can be overcome by tailoring and contextualising information to focus on the implications of particular sectoral and importantly also crosssectoral impacts of climate change (both direct and indirect). This could come, for example, in the form of modelled impacts (e.g. IAVs) showing sector-specific and cross-sectoral implications of the non-climate (but climate influenced) impacts. This information would be more consistent with existing individual and institutional decision-making processes, and would therefore be more likely to be used in the adaptation decision context. The institutional barriers associated with the political process and policy cycles are greater challenges to overcome. This work has shown how important it is to begin any adaptation decision-making work with adequate diagnosis and framing of the problem; this includes identifying that much of the problem of adapting to climate change is in fact institutional. This is a widely recognised fact, and an area that would benefit from co-produced research.

Uncertainty is not considered to be a significant barrier to adaptation action; however, a different approach should be taken to working uncertain climate projections into decision-making (Dessai et al. 2009). Qualitative, descriptive uncertainty terms are more closely aligned with existing decision-making processes and are, therefore, more likely to be correctly understood and used.

Understanding challenges for individual and collective action for adaptation decision-making processes provides important evidence to assist with contextualising climate change information. Participatory approaches such as this one are needed in this process to assist with the recognition and integration of diverse knowledge types about adaptation decision-making and how to overcome the existing barriers. Such approaches address the need for deliberate and ongoing learning about adaptation decision-making. The outcomes of this research are helping climate modellers within the IMPRESSIONS project (www.impressions-project.eu) to create usable, cross-sectoral, decision-centred information that can support decision-makers in including HECC scenarios in their efforts to adapt to climate change. This information is more likely to be usable in the intended policy setting and therefore to enhance resilience. The results of this research should be seen as further encouragement to the slow, but distinct, change in the direction of applied research agendas that continues to build momentum in the climate change science community.

Acknowledgements The research leading to these results has received funding from the European Community's Seventh Framework Programme (FP7/2007-2013) under grant agreement no 603416, IMPRESSIONS Project (IMPRESSIONS - Impacts and Risks from High-End Scenarios: Strategies for Innovative Solutions (www.impressions-project.eu). The authors would like to thank SNIFFER and the interview participants for their generous support and for offering their time.

Open Access This article is distributed under the terms of the Creative Commons Attribution 4.0 International License (http://creativecommons.org/licenses/by/4.0/), which permits unrestricted use, distribution, and reproduction in any medium, provided you give appropriate credit to the original author(s) and the source, provide a link to the Creative Commons license, and indicate if changes were made.

\section{References}

Adger, WN (2010) Social capital, collective action, and adaptation to climate change. In Der klimawandel, pp. 327-345. VS Verlag für Sozialwissenschaften

Adger WN, Arnell NW, Tompkins EL (2005) Successful adaptation to climate change across scales. Glob Environ Chang 15(2):77-86

Adger WN, Dessai S, Goulden M, Hulme M, Lorenzoni I, Nelson DR, Naess LA, Wolf J, Wreford A (2009) Are there social limits to adaptation to climate change? Clim Chang 93(3-4):335-354 
Alfieri L, Feyen L, Dottori F, Bianchi A (2015) Ensemble flood risk assessment in Europe under high end climate scenarios. Glob Environ Chang 35:199-212

Attride-Stirling J (2001) Thematic networks: an analytic tool for qualitative research. Qual Res 1(3):p385-485

Berkhout F, Hertin J, Gann DM (2006) Learning to adapt: organisational adaptation to climate change impacts. Clim Chang 78(1):135-156

Biernacki P, Waldorf D (1981) Snowball sampling: problems and techniques of chain referral sampling. Sociol Methods Res 10:141-163

Bryson J, Piper J, Rounsevell M (2010) Envisioning futures for climate change policy development: scenarios use in European environmental policy institutions. Environ Policy Governance 20(5): 283-294

Crabbé P, Robin M (2006) Institutional adaptation of water resource infrastructures to climate change in Eastern Ontario. Clim Chang 78(1):103-133

Cuevas SC (2016) The interconnected nature of the challenges in mainstreaming climate change adaptation: evidence from local land use planning. Clim Chang 136:661. doi:10.1007/s10584-016-1625-1

Daron JD, Sutherland K, Jack C, Hewitson BC (2015) The role of regional climate projections in managing complex socio-ecological systems. Reg Environ Chang 15(1):1-12

Dessai S, Hulme M, Lempert R, Pielke RA Jr (2009) Do we need better predictions to adapt to a changing climate? Eos 90:111-112

Dunn MR, Lindesay JA, Howden M (2015) Spatial and temporal scales of future climate information for climate change adaptation in viticulture: a case study of user needs in the Australian winegrape sector. Aust J Grape Wine Res 21(2):226-239

Eisenack K, Moser SC, Hoffmann E, Klein RJ, Oberlack C, Pechan A, Rotter M, Termeer CJ (2014) Explaining and overcoming barriers to climate change adaptation. Nat Clim Chang 4(10):867-872

European Commission (2015) A European research and innovation roadmap for climate services. DG Research and Innovation, Brussels

Füssel H (2007) Vulnerability: a generally applicable conceptual framework for climate change research. Glob Environ Chang 17(2):155-167

Gasser T, Guivarch C, Tachiiri K, Jones CD, Ciais P (2015) Negative emissions physically needed to keep global warming below 2 [deg] C. Nature communications, 6

Golledge NR, Kowalewski DE, Naish TR, Levy RH, Fogwill CJ, Gasson EG (2015) The multi-millennial Antarctic commitment to future sea-level rise. Nature 526(7573):421-425

Gramberger M, Zellmer K, Kok K, Metzger MJ (2015) Stakeholder integrated research (STIR): a new approach tested in climate change adaptation research. Clim Chang 128(3-4):201-214

Grothmann T, Patt A (2005) Adaptive capacity and human cognition: the process of individual adaptation to climate change. Glob Environ Chang 15(3):199-213

Harrison PA, Holman IP, Berry PM (2015) Assessing cross-sectoral climate change impacts, vulnerability and adaptation: an introduction to the CLIMSAVE project. Clim Chang 128(3-4):153-167

Harrison PA, Dunford RW, Holman IP, Rounsevell MD (2016) Climate change impact modelling needs to include cross-sectoral interactions. Nature Climate Change. Published online, 23 May. doi: 10.1038 /NCLIMATE3039

Heckbert S, Baynes T, Reeson A (2010) Agent-based modeling in ecological economics. Ann N Y Acad Sci 1185:39-53

High-end climate research EU website (2016) www.highendclimateresearch.eu [Accessed 12/10/16]

Holman IP, Harrison PA, Metzger MJ (2016) Cross-sectoral impacts of climate and socio-economic change in Scotland: implications for adaptation policy. Reg Environ Chang 16(1):97-109

Howden M, Jacobs KL (2015) Innovations in assessment and adaptation: building on the US national climate assessment. Climatic Change, 1-15

IPCC (2014) Pachauri RK, Allen MR, Barros VR, Broome J, Cramer W, Christ R, Church JA, Clarke L, Dahe Q, Dasgupta P, Dubash NK (2014) Climate Change 2014: Synthesis Report. Contribution of Working Groups I, II and III to the Fifth Assessment Report of the Intergovernmental Panel on Climate Change

Jäger J, Rounsevell MDA, Harrison PA, Omann I, Dunford R, Kammerlander M, Pataki G (2015) Assessing policy robustness of climate change adaptation measures across sectors and scenarios. Clim Chang 128(3-4):395-407

Jones, L, Champalle, C, Chesterman, S, Cramer, L, Crane, TA (2016) Constraining and enabling factors to using long-term climate information in decision-making. Climate Policy, 1-22.doi: 10.1080 /14693062.2016.1191008>

Jordan A, Rayner T, Schroeder H, Adger N, Anderson K, Bows A, Quéré CL, Joshi M, Mander S, Vaughan N, Whitmarsh L (2013) Going beyond two degrees? The risks and opportunities of alternative options. Clim Pol 13(6):751-69

Lemos MC, Rood RB (2010) Climate projections and their impact on policy and practice. WIREs Climate Change 1:670-682 
Lemos MC, Kirchhoff CJ, Ramprasad V (2012) Narrowing the climate information usability gap. Nat Clim Chang 2:789

Lemos MC, Kirchhoff CJ, Kalafatis SE, Scavia D, Rood RB (2014) Moving climate information off the shelf: boundary chains and the role of RISAs as adaptive organizations. Weather Climate Society 6(2):273-285

Lourenço TC, Rovisco A, Groot A (2014) Chapter 3: making adaptation decisions under uncertainty: lessons from theory and practice. In: Lourenço TC, Rovisco A, Groot A, Nilsson C, Füssel H-M, Van Bree L, Street RB (eds) Adapting to an uncertain climate (pp. 139-162). Springer International Publishing, Heidelberg

Lourenço TC, Swart R, Goosen H, Street R (2015) The rise of demand-driven climate services. Nat Clim Chang. doi: $10.1038 /$ nclimate 2836

Mase AS, Prokopy LS (2014) Unrealized potential: a review of perceptions and use of weather and climate information in agricultural decision-making. Weather Climate Soc 6(1):47-61

Mastrandrea MD, Field CB, Stocker TF, Edenhofer O, Ebi KL, Frame DJ, Held H, Kriegler E, Mach KJ, Matschoss PR, Plattner G-K, Yohe GW, Zwiers FW (2010) Guidance Note for Lead Authors of the IPCC Fifth Assessment Report on Consistent Treatment of Uncertainties. Intergovernmental Panel on Climate Change (IPCC). Available at: https://www.ipcc.ch/pdf/supporting-material/uncertainty-guidance-note.pdf

Murray-Rust D, Brown C, Van Vliet J, Alam SJ, Robinson DT, Verburg PH, Rounsevell M (2014) Combining agent functional types, capitals and services to model land use dynamics. Environ Model Softw 59:187-201

Ostrom E (1990) Governing the commons: The evolution of institutions for collective action. Cambridge University Press, Cambridge.

Parliament of Scotland (2009) Climate Change (Scotland) Act 2009. Edinburgh, UK.

Poteete AR, Ostrom E (2004) In pursuit of comparable concepts and data about collective action. Agric Syst 82(3):215-232

Powell, WW, DiMaggio, PJ (Eds.) (2012) The new institutionalism in organizational analysis. University of Chicago Press

Schewe J, Heinke J, Gerten D, Haddeland I, Arnell NW, Clark DB, Dankers R, Eisner S, Fekete BM, ColónGonzález FJ, Gosling SN (2014) Multimodel assessment of water scarcity under climate change. Proc Natl Acad Sci 111(9):3245-50

Schlierf K, Meyer M (2013) Situating knowledge intermediation: insights from science shops and knowledge brokers. Science and Public Policy, 1-12

Scottish Government (2011) Public bodies climate change duties: putting them into practice. Guidance required by part 4 of the Climate Change (Scotland) Act 2009. ISBN: 978-0-7559-9965-1 (web only). Available online at: http://www.gov.scot/Resource/Doc/340746/0113071.pdf

Scottish Government (2013) Climate Ready Scotland: Draft Scottish Climate Change Adaptation Program. Available online at: http://www.gov.scot/Resource/0042/00426516.pdf

Skourtos M, Tourkolias C, Damigos D, Kontogianni A, Harrison PA, Berry P (2015) Incorporating cross-sectoral effects into analysis of the cost-effectiveness of climate change adaptation measures. Clim Chang 128(3-4): 307-321

Smith MS (2015) 3. Responding to Global Environmental Change. In Bammer G [Ed.] Change! Combining Analytic Approaches with Street Wisdom. Australian National University Press, Canberra. Available online at: http://press. anu.edu.au/apps/bookworm/view/Change!+Combining+Analytic+Approaches+with+Street+Wisdom/11671/ch03. xhtml

SNIFFER website (2015) Sustainable development and climate resilience for Scotland. Available at: http://www. sniffer.org.uk/ [accessed 23/12/15]

Stafford Smith M, Horrocks L, Harvey A, Hamilton C (2011) Rethinking adaptation for a 4 C world. Philosophical Transactions of the Royal Society of London A: Mathematical, Physical and Engineering Sciences 369(1934):196-216

Street RB, Nilsson C (2014) Introduction to the use of uncertainties to inform adaptation decisions. In Adapting to an Uncertain Climate, pp. 1-16. Springer International Publishing

Tribbia J, Moser SC (2008) More than information: what coastal managers need to plan for climate change. Environ Sci Pol 11(4):315-328

Turnhout E, Stuiver M, Klostermann J, Harms B, Leeuwis C (2013) New roles of science in society: different repertoires of knowledge brokering. Science and Public Policy, 1-12

Weinstein ND (1980) Unrealistic optimism about future life events. J Pers Soc Psychol 39(5):806

Wyborn C, van Kerkhoff L, Dunlop M, Dudley N, Guevara O (2016) Future oriented conservation: knowledge governance, uncertainty and learning. Biodivers Conserv 25(7):1401-1408 